industry representatives and a few scientists, carries out an annual evaluation of every science project funded by government agencies. It uses subcommittees to prioritize according to four grades $\mathrm{S}$ (for superior), A, B and C - on the basis of scientific innovation, international competitiveness and degree of social contribution.

Increasingly, and this year in particular by all accounts, the system bears little resemblance to an objective, independent assessment. This can be a serious problem for major initiatives involving numerous laboratories and hundreds of millions of yen. One problem is a quota system for grades that can be arbitrary and unfair. Such grade quotas need not be a problem if they are applied on a sliding scale that takes into account objective, well-based judgements of achievement across disciplines. But that is not what happens. Too often, judgements, often based on a single day's visit to a project's group leader, don't do more than scratch the surface of a project's significance.

Another problem is that the committee is entirely Japanese. There is of course a limit to how much international experts can be involved. But an international perspective would seem obligatory, particularly when assessing large projects, some of which depend on international collaboration and represent a world-class effort costing many billions of yen.

But the worst failing of the system is a progressive distortion of supposedly objective assessment by the priorities and preferences of the committee and government. After discussions in closed rooms, ratings emerge that in many cases bear no relationship to scientific achievement or potential, and seem to defy explanation. A major project may be graded ' $S$ ' for two years in a row and then be graded A despite maintaining its performance. Even worse, some cutting-edge projects, after many years of top-level grades, have this year been graded ' $\mathrm{C}$ ' for no conceivable scientific reason.

Some might argue that scientific spending, like other funding, must follow government priorities and so be subject to "Scientific assessment
should be objective, well considered andtransparent to those being assessed." abrupt changes. No one would suggest that national priorities should remain fixed. But for the process to be nationally and internationally credible, and for top-notch scientists to believe that Japan is a good place to spend their best years, the system of evaluation must be revised. Many researchers see it as opaque and apparently arbitrary. Japan may not be unique - other leading countries also lack a clear evaluation process - but this does not make it acceptable.

Scientific assessment should be objective, well considered and transparent to those being assessed. It should be kept distinct from the process of priority setting, which should itself be open, and should involve greater participation of researchers before final decisions are reached.

\section{A recipe for trouble}

\section{A prestigious research agency should have thought twice before attaching its name to a diet book.}

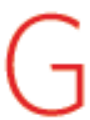
oing on a diet is a popular new year's resolution. This year, a diet book penned by researchers in Australia is set to turn up in many Christmas stockings. But its runaway success could damage the reputation of Australia's foremost research institution (see page 1060).

The diet book in question is by no means ground-breaking. Its high-protein message is not that different from others that have drifted into fashion in the past few years. But this one bears the badge of Australia's Commonwealth Scientific and Industrial Research Organisation (CSIRO).

In some parts of the world, it might seem odd that splashing the name of a scientific institution on the cover would shift copies of a book to the public. But CSIRO - which runs Australia's main network of government laboratories - has an unusually good public reputation. It is widely perceived as a trusted national institution. Its history, including its pivotal role in the development of agriculture and mining in Australia, has left a strong impression that it knows how to put science to good use.

But the commercial success of the book, which knocked Harry Potter and The Da Vinci Code off the national bestseller perch, is irritating some scientists, and for good reason.

The benefits of a high-protein diet remain a hot topic of debate among nutritionists. But even some of those who approve of such a diet question whether it should rely as heavily on meat as this one does, given the health risks associated with high meat consumption.

But what really rankles with the book's critics is the way it is being marketed. There's something decidedly unsavoury about using the phrase "scientifically proven" to sell anything to a trusting public, yet this is writ large on the book's front cover. The diet is also being promoted as being beneficial for everyone, whereas the published research indicates that it is superior to a high-carbohydrate diet only for a subpopulation of overweight women with symptoms of metabolic dysfunction.

Furthermore, the research behind the book was largely funded by the meat and dairy industries, whose products feature prominently in the diet. Detractors say that this aspect should have been more explicitly recognized, instead of being buried in the book's acknowledgements. The authors insist that the sponsors had no influence on the book's content, but the impression remains of a conflict of interest.
"There's something decidedly unsavoury about using the phrase 'scientifically proven' to sell anything to the public, yet this is writ large on the book'sfront cover."
To be fair, the book was not the idea of the researchers or even CSIRO's management. It came from a wily commercial publisher who spotted an opportunity. CSIRO, which has its own publishing arm, only reaps a small percentage of the profits in the form of royalties to its nutritional-research division.

Defenders of the book will argue that its success illustrates how to translate research into an accessible and popular format that puts science into practice. But that argument doesn't justify CSIRO giving permission for its name to be used in a way that could ultimately taint its hard-earned reputation. 